\title{
Vasstelling van Wins in Besigheid
}

(Inougurele Rede gehou by die aanvaarding van die Buitengewone Professoraat in Rekeningkunde en Ouditkunde aan die P.U. vir C.H.O., op 19 September 1958, deur prof. J. A. Grové).

Dit is die taak van die rekenmeester en ouditeur om die vasstelling van wins i 1 ' $n$ besigheid te sertifiseer in terme van die bepalings van die Maatskappywet van 1926 soos gewysig. Onder andere bepaal artikels 90 ter en 90 quat dat elke Winsin Verliesrekening van 'n maatskappy so opgemaak moet word dat dit vir sover redelik doenlik 'n juiste opgawe moet toon van die winste en verliese vir die tydperk waaroor dit loop, en dat elke Balansstaat van 'n maatskappy so opgemaak noet word dat dit die toestand van die maatskappy se sake op die datum van die Balansstaat getrou en juis sal weergee.

Dit is van die grootste belang dat daar 'n juiste vasstelling van die wins sal plaasvind, want 'n behoorlike vasgestelde wins sal die eienaar of bestuur van enige besigheid in staat stel om deur middel van ontleding die doeltreffendheid van produksie, die opbrengs op belegde kapitaal en die geskiktheid van uitbreiding te beoordeel.

Dit is ' $n$ algemeen aanvaarde feit dat betroubare syfers van die grootste nut vir die bestuur van enige besigheid is - immers, betroubare boekhouding is een van die steunpilare in enige besigheidsonderneming.

Indien ons die invloed van elektroniese en outomatiese werkverrigting op die taak van die rekenmeester en ouditeur besien, moet ons besef dat ook die grootste gedeelte van sy roetinewerk uitgeskakel gaan word. Die noodsaaklikheid van die kontrolewerk sal tot groot hoogte verdwyn. Hy sal dus genoodsaak wees om 'n meer positiewe bydrae te lewer, hoofsaaklik in die vorm van voorligting. Die tegniek van boekhouding sal deur masjiene vervang word, en daarom is dit my oortuiging dat daar in die nabye toekoms deur ons as rekenmeesters en ouditeurs dieper in die teorie gedelf sal moet word om sodoende 'n vaster en gesonder basis vir ons opinies te vind.

Ek wil by hierdie geleentheid poog om die rekenmeester se begrip van wins van nader te beskou en dan enkele suggesties vir verbeterde metodes aan die hand te doen.

John B. Canning het in 1929 in sy werk "The Economics of Accountancy" die volgende opmerking kwytgeraak:

„A diligent search of the literature of accounting discloses an astonishing lack of discussion of the nature of income. One should hardly expect that the profession which, above all others, is most constantly engaged in the statistical treatment 
of income should have found almost nothing at all to say about the nature of the thing they measure so carefully".

Hierdie toestand het in die latere jare verbeter, maar dat daar nog 'n groot gaping tussen die beskouings van die ekonoom en die rekenmeester lê, is sonder twyfel waar. In die verhandeling "Wins" deur dr. F. J. du Plessis van hierdie Universiteit is hierdie verskil in begrippe duidelik na vore gebring.

Oor die algemeen gesproke kan ons in alle billikheid ooreenstem oor die formele definisie van wins, wat as volg gestel kan word:

„Die wins gedurende 'n spesifieke periode verdien, is gelyk aan die verbruik plus die verandering (positief, of negatief) in kapitale waarde wat gedurende dié periode plaasgevind het en wat in die volgende vergelyking uitgedruk kan word:

Wins = Onttrekkings gedurende 'n spesifieke periode plus nettowaarde aan die einde van dié periode minus nettowaarde aan die begin van dié periode."

Ongelukkig is die drie faktore van hierdie vergelyking nie presies omlynde begrippe nie. Die faktor "onttrekkings" kan met die hoogste mate van objektiwiteit bepaal word, aangesien dit hoofsaaklik die vorm van onttrekkings van kontant of die private verbruik van goedere aanneem. (Natuurlik ontstaan die belangrike probleem van koopkrag hier, maar hierdie probleem sal nie hier behandel word nie).

Die werklike probleme ontstaan wanneer ons probeer om die faktore "Nettowaarde aan die einde" en "Nettowaarde aan die begin", wat die kapitale waardes in die Balansstaat verteenwoordig, vas te stel.

As ons ons bespreking op ekonomiese teorie baseer, kan bogenoemde faktore in omlynde begrippe omskep word en sodoende kan ons die begrip wins definieer. Ons sal in staat wees om te bepaal wat ons onder die term "elkonomies juiste wins" verstaan.

Om kapitaal in ekonomiese terme te besit, beteken om die seg op alle toekomstige opbrengste van een of meer bates te hê. Die kapitale waarde van 'n bate word dus uitsluitlik bepaal deur die opbrengs wat dit vir die besitter in die toekoms sal lewer. In die geval van 'n besigheid word die kapitale waarde dus vasgestel deur die bedrag van onttrekkings of opbrengste wat die eienaar verwag om van die besigheid te ontvang solank dit in sy besit is. (Daarby word dus ook ingesluit enige toekomstige bedrag wat hy mag ontvang wanneer hy 'n eiendomsreg aan iemand anders oordra).

Die ekonomiese teorie gebruik die vergelyking van verdiskontering om die kapitale waarde vas te stel. Om dus op enige tydstip die juiste kapitale waarde van 'n besigheid (of van ' $n$ individuele bate) vas te stel, moet ons in staat wees om algehele kennis van wat die toekoms inhou, te hê, met betrekking tot die opbrengste wat die besigheid sal oplewer en die rentekoers wat gebruik moet word.

Hierdie abstraksie nit die werklike wêreld stel ons in staat om die inhoud van "nettowaarde aan die einde" en „,nettowaarde aan die begin" presies te definieer 
en gevolglik kan ons in juiste teoretiese l,egrip rorm van wins, wat ons "die jdeale wins" kan noem. Hierdie begrip kan eenvoudig as rente van die kapitale waarde tan die bate gedefinieer word.

Dit is vanselfsprekend dat die veronderstelling van algehele kennis van die toekoms nie in die werklike lewe bewaarheid kan word nie. Ons is verplig om ons veronderstellings met betrekking tot die toekoms aan die einde van elke rekening. kundige periode in hersiening te neem. Gevolglik most ons die kapitale waarde in hersiening neem.

Hieruit spreek een belangrike feit, naamlik tat die ekonomiese manier van dink op die teorie berus dat die waardasie van kapitale waarde gemaak mott word op die basis van die verwagte toekoms en nie op die basis van die sogenaamdr feite van die verlede nie.

Dit is op hierdie stadium feitlik oorhodig om te meld dat die rekeningkundige hegrip van wins van die hierbo omlynde, ,ideale begrip" verskil. Hoe groot die verskil in hierdie twee begrippe werklik kan wees, wil ek aan u voorhou aan die hand van resultate van 'n ondersoek wat deur prof. P. Hansen van Denemarke van 'n werklike geval in besigheid gedoen is.

Nadat die besigheid waar hierdie ondersoek plaasgevind het, vir 11 jaar bestaan het, het dit in finansiële moeilikhede beland. Die besigheid is geforseer om al sy aandele te verkoop, en hierdie aandele het 72,000 krone opgelewer.

Hierdie 72,000 krone, in die vasstelling van die ideale wins, word beskou as ' anduiding van die eindwaarde van die aandele, wat in hierdie geval die ekwivalent van die likwidasiewaarde is. Hierdie eindwaarde, tesame met die periodieke onttrekkings in die vorm van dividende soos in die rekeninge aangetoon, het die basis gevorm vir 'n berekening wat eerstens die werklike kapitale waarde aan die einde van die verskillende rekeningkundige periodes en tweedens die ideale winste (gerealiseerde kapitale rente) aangetoon het. Die kapitalisasie is teen $8 \%$ rente per jaar deurgevoer.

Die berekening van wins, onttrekkings (insluitende die likwidasieprys) en kapitale waarde, volgens rekeningkundige heginsels, het die volgende informasie blootgelê.

\section{Rekeningkundige} Wins

1.1 .1942

1.1 .1943

1.1.1944

1.1 .1945

1.1 .1946

1.1.1947

1.1 .1948
16,000

28,000

36,000

37,000

23,000

34,000

29,000
Onttrekkings Rekeningkundige (Dividende)

11,000

5,000

17,000

18,000

13,000

27,000

27,000
Nettowaarde

44,000

49,000

72,000

91,000

110,000

120,000

127,000

129,000 


\begin{tabular}{rrcr} 
I.1.1949 & 19,000 & 19,000 & 129,000 \\
1.1 .1950 & 27,000 & 21,000 & 135,000 \\
1.1.1951 & 20,000 & 19,000 & 136,000 \\
1.1.1952 (voor likwidasie) & $-10,000$ & - & 126,000 \\
1.1.1953 (na likwidasie) & $-54,000$ & - & $\mathbf{7 2 , 0 0 0}$ \\
& & & \\
& & & \\
\hline
\end{tabular}

In die volgende tabel is die ideale wins en juiste kapitale waarde vasgestel I. .m.v. vergelyking van verdiskontering op die basis van onttrekte dividende en die gerealiseerde likwidasiewaarde van die andele $(72,000$ krone) wat tesame die totale ontrekkings deur aandeelhoners vir die periode 1-1-1941-1.1-1952 verteenwoordig.

1.1 .1941

1.1 .1942

1.1.-1943

$1-1-1944$

$1-1-1945$

I.1.1946

1-1-1947

I-1. 1948

I-1-1949

1.1-1950

1-1-1951

1-1-1952

$$
\begin{gathered}
\text { Ideale Wins } \\
\text { (Kapitale Rente) }
\end{gathered}
$$

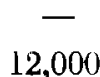

11,000

12,000

12,000

11,000

11,000

10,000

8,000

7,000

7,000

5,000

$$
\begin{aligned}
& \text { Onttrekkings } \\
& \text { (Dividende) }
\end{aligned}
$$

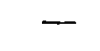

11,000

5,000

17,000

18,000

13,000

27,000

27,000

19,000

21,000

19,000
Juiste kapitale Waarde

143,000

144,000

150,000

145,000

139,000

137,000

121,000

104,000

93,000

79,000

67,000

72,000

106,000

Wanneer hierdie twee berekenings van kapitaal op 'n diagram geplaas word, blyk dit duidelik (soos hieronder getoon) dat die kapitale waardes in lynregte teenstelling met mekaar ontwikkel het. 


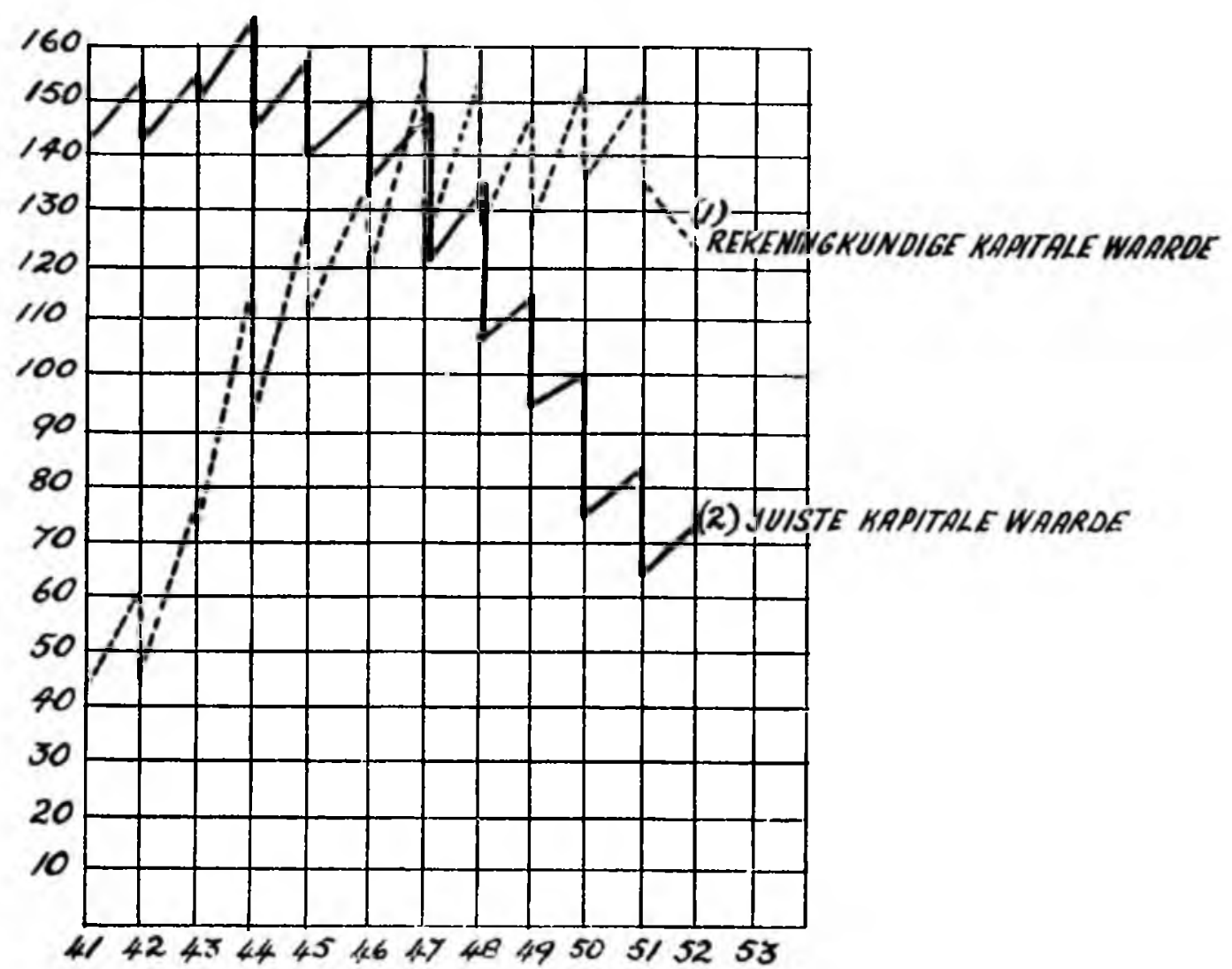

Juiste en Rekeningkundige berekening van kapitale waarde.

Die grafiek van rekeningkundige berekenings toon vir al die jare behalwe die laaste jaar dat die jaarlikse verdiende winste die onttrekkings oorskry wat as gevolg 'n altyd toenemende kapitale waarde van 44,000 krone tot 126,000 krone het. Die grafiek van die juiste kapitaal toon aan dat in al die jare behalwe die eerste twee en die laaste een die onttrekkings die winste (d.i. die rente op die kapitaal) oorskry het. Gevolglik het die juiste waarde van die netto bates nie toegeneem nie, maar gedaal van 143,000 krone tot 72,000 krone.

Sonder om verder in hesonderhede te gaan, kan die volgende bewering gemaak word:

Daar bestaan $n$ verskil in prinsipe tussen die resultate van die twee berekeninge en gevolglik ook in die inhoud van die twee begrippe van wins.

Hieruit kan gevolglik ook beweer word dat deur vas te hou aan konserwatiewe rekeningkundige heginsels, ons hoegenaamd geen waarborg het dat ons kapitale vasstellings konserwatief sal wees nie; verder ook dat ons definitief nie kan verwag 
dat ons rekeningkundige metodes aan ons 'n konserwatiewe winssyfer sal verstrek nie.

Die vernaamste indruk bly dat deur gebruik te maak van die tradisionele rekeningkundige metodes van waardebepaling van bates en laste, ons nie in staat is om aan eienaars of bestuur inligting te gee insake die skeidslyn tussen werklike wins en verbruik (of toename) van kapitaal nie. Die rekeningkundige begrip van wins mag verbruik van kapitaal insluit en mag ook toename in kapitaal (geheel of gedeeltelik) uitsluit.

Uit die verstrekte syfers kan gesien word dat die totale rekeningkundige wins vir die hele lewe van die besigheid op 205,000 krone te staan kom. Hierdie bedrag bestaan egter uit 106,000 krone werklike wins en 99,000 krone verbruik van kapitaal.

Uit die hierbo aangehaalde ondersoek kom ons dus tot die gevolgtrekking dat rekeningkundig-bepaalde winste soms onrealisties en soms selfs oor-optimisties kan wees, nieteenstaande die feit dat ons algemeen aanvaar dat ons metodes deurgaans konserwatief is.

Waarom bestaan daar dan so iets as positiewe of negatiewe onsigbare kapitale waardes?

Een van die redes is sekerlik die feit dat ons nie in staat is om die toekoms met ' $n$ voldoende graad van sekerheid te voorspel nie.

'n Ander belangrike rede is egter die feit dat die jaarlikse rekeningkundige wins- en kapitaalsyfers op 'n stel reëls (of konvensies) berus wat rekeningkundige berekeninge van ekonomiese berekeninge laat verskil.

Ek sal probeer om 'n paar kenmerkende voorbeelde uit die rekeningkundige praktyk te neem om aan die hand daarvan aan te toon watter konvensies ons in ons vak lei, om sodoende ' $n$ indruk te kry van die gevolge wat dit op die bepaling van wins en kapitale waardes het.

Die aanvaarde rekeningkundige praktyk berus hoofsaaklik op die volgende vyf breë beginsels, nl. :

(1) Die waarde van bates wat nie vir herverkoop bestem is nie, behoort op hul kosprys, ongeag hul markwaarde, gebaseer te word.

(2) Die waarde van bates wat vir verkoop bestem is, behoort op hul kosprys of markwaarde, welke die laagste is, gebaseer te word.

(3) 'n Blote styging in markwaarde is nie 'n wins nie, maar as die bate vir herverkoop gehou word, is 'n daling in markprys 'n verlies.

(4) Niks anders as 'n voltooide verkoopstransaksie kan 'n wins of verlies meebring nie.

(5) In die algemeen gesproke is "benede pari” opgawes konserwatief en aanbevelenswaardig; "bo pari" opgawes oneerlik en laakbaar.

Die voorraderekening van 'n handelsonderneming lê een van die mees kenmerkende rekeningkundige konvensies bloot. $D$ it is die beginsel om realisasie as die enigste kriterium vir die bepaling van verkope te gebruik. Die vierde beginsel 
hierbo genoem hepaal dit ook so: .i iks anders as 'n voltooide verkoopstransaksie kan 'n wins of verlies meebring nie". Die gevolge hierran is:

(1) Die verkoophlare goedere in voorraad an die einde van die finansiële jaar kan slegs teen kosprys of markwaarde. welke die laagste is, op die voorraderekords aangebring word (vergelyk die tweede beginsel hierbo genoem).

(2) Die Balansstaat kan nie items wat die waarde van ander aktiwiteite met hetrekking tot verbruikerstransaksies verteenwoordig, wat toekomstige inkomstes of onkostes as gevolg sal hê,, bevat nie.

Hierdie metode in die rekeningkunde reguleer dus nie alleen die vloei van inkomstes na die Wins- en Verliesrekening nie, maar reguleer ook die vloei van onkostes na die Wins. en Verliesrekening. Dit is so kensketsend van rekeningkunde, maar uit 'n ekonomiese gesigspunt gesien so ontoepaslik. Die rekenmeester sê : Dit is die beskouing van wat in die Wins-en Verliesrekening as inkomste ingesluit behoort te word wat hepaal watter items in die Balansstaat ingesluit mag word en hoe dit waardeer behoort te word. Die ekonoom sê: Die waarde van bates en laste behoort eers op die basis van 'n beraming van hul toekomstige opbrengs vasgestel te word, waarna die inkomstes en uitgawes as 'n gevolg daarvan verkry sal word.

In die begrip „,kosprys of markwaarde, welke die laagste is”, vind ons 'n rersagting van die basiese rcël dat die goedere teen kosprys waardeer moet word. Ons as rekenmeesters is baie gesteld op hierdie beginsel, omdat ons voel dat dit tot konserwatiewe bepaling van winste en kapitaalwaardes lei. Die gebruik van die beginsel „kosprys of markwaarde. welke die laagste is", beïnvloed egter nie ons konvensie om inkomste op in verkope-hasis te realiseer nie. Hierdie konvensie is universeel, ongeag welke hasis van waardasie ons gebruik. Op sy beste kan dit gesê word dat hierdie heginsel 'n sekere mate van toenadering tot die ekonoom se waardasie met betrekking tot die voorraadrekening verteenwoordig, en slegs dan wanneer 'n toekomstige daling in die prys van die verbruikers-artikel verwag word.

Daar ontstaan 'n menigte effekte, of ons nou „kosprys of markwaarde, welke die laagste is", of kosprys as 'n basis van waardasie van voorrade neem, wat hul oorsprong in aankoop- en verkooptransaksies het wat voor die einde van die finansiële periode begin en wat nie bejaal en gevolglik nie in die winste of kapitale waardes ingesluit kan worl nie. Dic effek daarvan kan dus nie geregistreer word roordat die transaksie roltooi is nie. Gevolglik bestaan positiewe of negatiewe onsigbare kapitale waardes noodwendig. en as eerste resultaat sal die wins ò 'n afname van onsighare kajitale waarde insluit (die wins is dus te hoog geskat), of 'n kapitale toename as gevolg van hierdie onsighare waardes uitgesluit, (m.a.w. die wins is te laag geskat).

Die behandeling van vaste bates laat ook verskil van mening ontstaan. Wanneer die „Vaste Paaiement-metode” van waardevermindering gebruik word en 'n waarde. verminderingskedule opgestel is, is die waardes wat in die toekomstige balansstate 
opgeneem moet word, reeds vooruit bepaal, sonder om in ag te neem dat die ekonomiese waarde (d.i. die vermoë van die bate om opbrengste te lewer) waarskynlik in 'n totaal verskillende manier van die een finansiële periode tot die ander sal wissel. Ook hier werk die rekenmeester volgens die ekonoom agterstevoor, want hy stel eers vas wat in die Wins- en Verliesrekening ingesluit sal word en dan word die waarde van die bate as 'n residu afgelei.

'n Interessante situasie. word gevind as ons kyk na die rekeningkundige behandeling van die werk wat deur werknemers, eienaars en bestuur gedoen word. Alle werk wat gedoen word, dra die vermoë om inkomste te verdien. Gevolglik het hierdie werkbydraes 'n kapitale waarde vir die besigheid en hierdie waarde, soos alle ander kapitale waardes, kan van tyd tot tyd fluktueer. Nieteenstaande dit is dit 'n ongeskrewe wet in die rekeningkundige wêreld dat so 'n kapitale waarde van menslike werksvermoë nie op die Balansstaat aangedui word nie. Gevolglik word die bepaling van die wins nie deur enige afname in hierdie kapitale waarde beinvloed nie; aan die ander kant word enige toename in hierdie kapitale waarde ook nie in die wins ingesluit nie.

Wie besef nie die groot bate van bekwame en betroubare personeel, 'n ervare direkteur, 'n uitmuntende bestuurder, rekenmeester of ander uitvoerende beampte nie? Dat dit moeilik gemeet kan word, is waar; maar dat dit gemeet moet word, is net so waar.

Daar moet nog op een belangrike punt klem gelê word. Selfs al sou ons veron derstel dat die Balansstaat en Wins- en Verliesrekening so verbeter word dat dit die baie items wat vandag nie ingesluit word nie, ornvat, dan nog sal ons nie 'n kapitale waardasie kry wat ekonomies realisties is nie. Ons sal ook moet poog om 'n aantal meer onomlynde, newelagtige, vae items wat die toekomstige inkomstes en uitgawes beinvloed, te waardeer en in te sluit. In ons pogings om hierdie kapitale waardes vas te stel, sal ons magte teëkom wat hul oorsprong buite die besigheid het, bv. in die voordelige of nadelige klimaat wat deur die samelewing geskep word. Ook sal ons omstandighede teëkom wat in die besigheid geskep word en wat die verdienstevermoë in ' $n$ positiewe of negatiewe rigting beïnvloed.

Al hierdie faktore mag in die klandisiewaarde (Goodwill) ingesluit wees, maar hierdie item mag slegs op die Balansstaat verskyn wanneer 'n bedrag geld daarvoor betaal is en mag dan slegs teen sy aankoopsprys getoon word. Bowendien word daar altyd gepoog om klandisiewaarde so vinnig as moontlik af te skryf sodat dit van die Balansstaat kan verdwyn. Ons metodes moet altyd die stempel van 'n konserwatiewe beleid dra!

Ons kan dus uit bostaande gegewens die gevolgtrekking maak dat die feit dat jaarlikse rekeningkundige rapporte nie as ekonomies juiste rapporte gekarakteriseer kan word nie, nie slegs aan ons onvermoë om in die toekoms te sien, te wyte is nie, maar ook aan die rekenmeester se verknogtheid aan sekere konvensies wat hom verhoed om sy rapporte 'n ekonomiese inhoud te gee. 
Ons het aangedui dat die rekeningkundige begrip van wins met dié van die ekonoom verskil. Ons sien dit in die Balansstaat waar die waardes van die items verskillend in oorsprong is. Sekere items word teen huidige waardes aangegee, (bv. kontant voorhande); andere teen hul toekomstige waarde (bv. wissels); andere teen "historiese koste"-waardes (bv. voorrade en onkoste-items wat oor 'n paar jaar versprei word). Verder word items gevind wat gewaardeer word volgens 'n vasgestelde skema wat verband hou met etlike toekomstige finansiële periodes en wat gebaseer is op 'n arbitrêre verdeling van die "historiese koste" geneem oor 'n sekere aantal finansiële jare soos bv. vaste bates. Die totale effek van bostaande is dieselfde as wanneer ons die eerste Balansstaat-item teen $20 /-$ per $\mathfrak{f}$ waardeer, die tweede teen $15 / \cdot$ per $f$, die derde teen $37 / 6 d$. en die vierde teen niks, en dan hierdie bedrae bymekaar tel en die eindbedrag gebruik om die grootte van die kapitale waarde aan te dui, - of, meer korrek, om die konserwatiewe grootte van dié waarde aan te dui. John Canning stel dit in sy voorheen aangehaalde werk ietwat anders: "What is set out as a measure of net income can never be supposed to be a fact in any sense at all except that it is the figure that results when the accountant has finished applying the procedure which he adopts."

Hieruit mag ons egter nie aflei dat 'n rekenmeester 'n apologeet nodig het nie - wat hy nodig het is 'n tolk! En in dié rol skitter die ekonoom.

Dit bly egter die verantwoordelikheid van die rekenmeester self om die nodige interpretasie aan sy state te gee. Die moderne enterpreneur steun op sy rekenmeester vir baie van die feite wat hy nodig het om sy besigheidsbeleid vas te stel. Dit moet egter in gedagte gehou word dat die besigheidsonderneming van vandag nie alleen werk nie; dit funksioneer in 'n ingewikkelde ekonomiese sisteem. Dit is dus die taak van die rekenmeester om hierdie ekonomiese verband te verstaan. Van watter nut kan die rekenmeester se aanbieding van feite wees as hy hierdie agtergrond nie het nie? Ons moet dus aanvaar dat 'n kennis van ekonomie 'n essensiële deel van die toerusting van 'n rekenmeester moet wees.

Insgelyks het die moderne ekonoom die dissipline van eksaktheid en 'n goeie waardering van kwantitatiewe faktore, wat rekeningkunde aanbied, nodig. Veral in hierdie tyd, waar teorie geneig is om ons buite die wêreld van feite te neem, kan daar nie te veel klem op die belangrikheid van 'n kennis om harde, koue feite vas te stel, gelê word nie. En dit is presies die veld van die rekenmeester.

Dit kom dus daarop neer dat die rekenmeester en die ekonoom 'n werkende kennis van die ander se terrein moet hê, bewus moet wees van hul onderlinge verwantskap en die feit dat hulle tot 'n groot mate van mekaar afhanklik is.

In die lig hiervan kan ons dus vra of die rekeningkundige begrip van wins dan 'n ander inhoud moet hê.

Ons het dus twee alternatiewe om van te kies:

Ons kan besluit dat ons jaarlikse rekeningkundige rapporte 'n ,historiese weergawe" sal wees, m.a.w. 'n poging om op rekord te plaas wat verdien is, sonder om aan te dui of dit ' $n$ inkomste of kapitale verdienste is. 
Ons kan egter ook probeer om die jaarlikse rekeningkundige rapporte vas te koppel aan ekonomiese waardasies en gevolglik ook probeer om tussen inkomste en kapitale verdienstes te onderskei.

Alles dui daarop dat ons ons jaarlikse rekeninge moet baseer op toekomstige waardebepalings, want aangesien hierdie rekeninge een van die instrumente is wat deur die bestuur en eienaars gebruik word in die bepaling van besigheidsbeleid, is dit slegs natuurlik om te eis dat dit sover moontlik 'n ekonomiese inhoud moet hê.

Indien ons sou besluit om in hierdie rigting te beweeg, sal daar noodwendig baie probleme vir die rekenmeester ontstaan. Hy sal al sy konvensies oorboord moet gooi en sal in al sy werk van die verlede na die toekoms moet oorskakel. Ingewikkelde probleme met betrekking tot waardasie sal ontstaan, want van hom sal verwag word om die onsigbare kapitaalwaardes in die Balansstaat op te neem, wat onder meer inhou dat ons sal probeer om die grootte van die bestaande positiewe of negatiewe klandisiewaarde aan te dui.

Daar kan egter ook 'n ander gedragslyn gevolg word, nl. om die leser in staat te stel om 'n opinie te vorm van die onsigbare kapitale waarde. Hiervoor is nodig dat die rapport wat die jaarlikse Balansstaat en Wins- en Verliesrekening vergesel, meer omvattend opgestel moet word. In hierdie rapport sal dan informasie gegee word wat betrekking het op faktore (positief en negatief) wat waarskynlik die verdienstevermoë van die besigheid sal beïnvloed en wat die rekenmeester nie kans gesien het om in die Balansstaat in te sluit nie. Die leser van 'n jaarlikse rekeningkundige rapport moet in feite dus die finale aansuiwerings self maak om tot die kapitale waarde van die besigheid, wat hy as realisties beskou, te kom. 'n Optimistiese beskouing oor die toekoms sal hom noop om 'n faktor by te tel wat „onsigbare kapitale waarde" verteenwoordig. 'n Pessimistiese beskouing van die toekoms sal hom 'n faktor laat aftrek van die kapitale waarde wat die rekenmeester in sy staat aangedui het.

Tot hoe 'n mate die beleggers en ekonome hiertoe in staat sal wees, hang tot 'n groot mate af van die omvang van addisionele informasie wat in die bykomende verslag van die rekenmeester vervat is, maar ook van die bekwaamheid van die lesers van hierdie finale rekeninge om 'n redelik gesonde oordeel oor die toekoms te vorm.

Graag gebruik ek hierdie geleentheid om my dank uit te spreek teenoor die hooggeagte lede van die Raad en Senaat van ons Universiteit vir die vertroue in my gestel om my in hierdie verantwoordelike betrekking aan te stel. 
Hooggeleerde Rektor (in sy afwesigheid), die waarnemende Rektor, Here Professore, Dames en Here Lektore, aan u betuig ek my dank vir u leiding en hulpvaardigheid.

Geagte Dames en Here Studente,

Geagte Dames en Here, ek dank u vir u welwillende gehoor.

Algemene Verwysings :

1. Baxter, W. T., Studies in Accounting (Sweet \& Maxwell, Landon, 1950).

2. Canning, J. B., The Economics of Accountancy (New York, 1929).

3. Du Plessis, F. J., Wins (M.Comm.-verhandeling, 1956).

4. Gillman, S., Accounting Concepts of Profit (Ronald Press, New York, 1939).

5. Hansen, P., Ascertainment of Profit (The Cost Accountant, Maart 1958).

6. Perry, K. W., Accounting and Economics (The Accounting Review, Julie 1958).

7. Taggert, P., Profits and Balance Sheet Adjustments (Pitman, London, 1934). 